\title{
African Urbanization: an Analytic Policy Guide ${ }^{1}$
}

Paul Collier ${ }^{2}$

January, 2016

\begin{abstract}
Africa is rapidly urbanizing: it is the most important structural transformation underway in the region. By 2050, almost regardless of government policies, its urban population will have tripled. But the consequences are critically dependent upon policy choices: successful urbanization requires active and far-sighted government. At its best, urbanization can be the essential motor of economic development, rapidly lifting societies out of mass poverty. At its worst, it results in concentrations of squalor and disaffection which ferment political fragility.

To date, African urbanization has been dysfunctional, the key indication being that cities have not generated enough productive jobs. If urban policies remain unchanged, future urbanization is likely to result in similar outcomes. This paper sets out how changed policies can unlock the potential of urbanization for prosperity. Primarily, it sets out the economic forces underlying this potential, and the specific policy actions they require. But policy actions do not just happen: they are generated by political processes that confer authority and capacity on public institutions. The paper concludes with a discussion of how politically urban policy-making might be improved.
\end{abstract}

\section{Introduction}

Successful urbanization is critical for national economic development. It benefits the rural population as much as those who move to towns. No rural population has ever reached OECD levels of prosperity without being part of successful national urbanization. Rural living standards are able to rise as people move to towns because each remaining person has more land on which to work, and because rising urban demand for food raises rural earning power.

Most African countries are still in the early stages of urbanization. Some, such as Ethiopia, are still overwhelmingly rural with only $20 \%$ of their population urbanized. But this will change

\footnotetext{
${ }^{1}$ This paper is part of a DFID-funded research project on urbanization in Africa and other developing regions managed by the World Bank under Somik Lall, and conducted by a joint team at Oxford University and the London School of Economics. It is jointly led by Paul Collier, Vernon Henderson and Tony Venables. The research is currently underway and so, while the paper draws on this new material, it is currently not yet available for referencing. Versions of this paper have been presented in Addis Ababa, Kampala and Washington DC, and at a meeting of the International Growth Centre at LSE.

${ }^{2}$ Professor of Economics and Public Policy at the Blavatnik School of Government, Oxford University and a Director of the International Growth Centre.
} 
rapidly as economies develop. The first industrial nation, Britain, exemplified this process. In 1800 only $20 \%$ of its population was urban; by 1900 only $20 \%$ was still rural. Not only will Africa's population move to the towns, but its overall population is still growing rapidly. In conjunction these forces will generate rapid growth in the number of people living in urban areas. A recent UN projection is for Africa's urban population to triple by 2050. In effect, two thirds of the urban space that Africa will have in 2050 does not yet exist and so must be built during the next 35 years. The existing third has been built gradually over the past century. The challenge is thus is to build twice as much in only one third of the time: in the next few decades urbanization will proceed around six times as fast as in the past century.

But it will not be enough to do six times more: Africa's urbanization to date has not been successful. A successful city provides the physical conditions in which ordinary workers can be productive, and ordinary households can live in decent surroundings. Building cities which meet either of these conditions is difficult; building cities which reconcile productivity with liveability requires investment that is both substantial and smart. No African city has yet achieved this combination and many are generating conditions that are so inadequate that the majority of their inhabitants can neither be productive, nor lead decent lives. Business as usual, even at a greatly increased rate, will result in mega-slums, not $21^{\text {st }}$ Century super-cities such as Singapore.

Getting urbanization right is not easy. The starting point is to understand how a successful city massively raises the productivity of ordinary people. It is this miracle of productivity that is the great engine of prosperity that has lifted the countries now in the OECD from the poverty that characterised the entire world until two centuries ago.

However, the miracle of productivity can all too easily generate a tragedy of squalid living conditions. The world's first industrial cities grew explosively in the North of England during the $19^{\text {th }}$ Century. Bradford became the most prosperous city in Europe, but its good conditions for production generated terrible conditions for living: in 1849 it was hit by a devastating cholera epidemic. More generally, the new miracle cities inadvertently generated living conditions so appalling that life expectancy collapsed. It took a revolutionary reinvention of urban public services to overcome this tragedy. Good urban public policy thus involves both an economic strategy to trigger the miracle of productivity, and a social strategy to overcome the tragedy of squalor.

\section{The Miracle of Productivity}

\section{Foundations}

In a traditional economy, such as characterized the entire world until 1800 and still characterizes African peasant agriculture, productivity is low and stagnant. In a modern economy it is not only much higher, but continuously rising. Adam Smith was the first economist to understand the sources of high and rising productivity. He understood them because he saw them happening around him in the early stages of industrialization. What he saw was the effects of scale and 
specialization. Some of these effects raise the level of productivity, but the more important enable it to keep increasing.

Scale makes people more productive. One reason is simply technological: a large container such as a boiler is more efficient than a small one. Some things have a minimum size: in Smith's day, the big innovation was for a water wheel to power machinery, but a water wheel had enough power to turn many machines so it was efficient to bring the machines together in a factory. Such technological scale economies raise the level of productivity.

Specialization also makes people more productive. The myriad of tasks that in aggregate are performed by workers in a modern economy each require a degree of skill. A fundamental feature of how productive a worker is in a task is how much time they have spent doing it, a process known as 'learning by doing'. This is true even for seemingly mundane tasks, but it becomes far more important with complexity. If a worker has to be a jack-of-all-trades, spreading time thinly over many different activities, there is little time for learning in each specific activity and so productivity remains low. Probably the most important component of the miracle of productivity is that by specializing on a single narrowly-defined task, a worker is able to concentrate his learning on acquiring the corresponding narrowly-defined skill. As a result, in aggregate the workforce accumulates far more human capital than if it were unspecialized. Similarly, by specializing in a narrowly-defined product or service, the management of a firm is able to concentrate its learning.

Scale and specialization interact. The most straightforward interaction is that scale enables specialization. At low volumes of production a task that requires only a very small proportion of the labour time required will not warrant having anyone dedicated to it. Hence, the larger is the scale of production the more specialized each worker can be. This is what Adam Smith recognized. But modern economies have moved far beyond the simple production technologies that astounded Smith. Production has become far more sophisticated through mastering complexity. In turn, mastering complexity depends upon being able to marshal vast amounts of knowledge. The capacity to generate and retain knowledge is quantized: for most of history the limit to knowledge was the capacity of the human brain. But the dramatic growth in the complexity of production over the past century has been driven not by bigger brains but by bigger firms. Scale and specialization have enabled a quantum increase in the capacity of firms to generate and store knowledge of production techniques (Hidalgo, 2015).

But scale and specialization are generated not only by what happens within firms, but what happens between them. Knowledge is quantized not just at the level of the brain and the firm, but in networks: as groups of firms specialize in interdependent activities, the productivity of the entire group is enhanced. In turn, the emergence of interdependence depends upon a large market: firms will be reluctant to specialize in a product that is so narrowly defined that it has only one customer. Similarly, workers will be reluctant to become completely specialized in a skill needed by only a single employer because they would lack bargaining power and be subject 
to 'hold-up'. These are examples of a further source of scale economies: the larger the market, the greater the specialization permitted without risk of 'hold-up'. Large markets bring other productivity gains. If to be technologically efficient a firm must be above some minimum size, then the larger is the market the more firms can co-exist. If a firm could learn only from its own experience, change would be very slow. But in a large market firms can learn from each other. This introduces a second means of learning: in addition to learning-by-doing, firms can learn by observing and copying. Further, in a large market they have a strong incentive to do so because scale makes markets more competitive. If the market is large enough to support ten firms it will be more competitive than if it can only support two. Competition is a spur to dynamic efficiency: firms struggle to innovate in order to get ahead of rival firms.

While scale and specialization permit productivity to increase dramatically, they also have a potential downside. Scale may weaken worker motivation to put in effort. A worker in a very small unit of production, such as a peasant farmer, market trader, or artisan, has a strong incentive to work because otherwise he goes hungry. But in a large organization there will be only a negligible connection between the effort of the individual worker and the ability of the firm to pay him. Similarly, specialization creates the need for workers to cooperate with each other, but does not automatically provide an incentive to do so. Organizations can only harness the potential of scale and specialization if they develop ways of motivating workers to put in effort and to cooperate. Typically, successful organizations reconcile scale and specialization with motivation by combining financial incentives linked to monitored performance, with workplace identities that help workers to share the objectives of the organization. A further benefit of competition is that only those firms which manage this reconciliation are able to survive.

Scale, specialization and motivation are the foundations of high productivity. We now turn to why these processes usually need cities in order to be ignited.

\section{The spatial implications of scale and specialization: connectivity}

Scale and specialization both have important spatial implications. Technological economies of scale can only be exploited if the product is produced, or the service performed, at a particular point. The various types of market economies of scale can only be exploited if a large number of producers are able to reach a common large group of consumers. Specialization in a particular skill is only possible if many complementary skills can be mustered together in the same location. Specialization in a particular product or service is only possible if the reachable market is sufficiently large.

The common requirement for these conditions to be met is connectivity. Producers must be sufficiently well-connected with consumers that both can transact in markets that are specialized yet competitive; workers must be sufficiently well-connected with firms that both can transact in markets that are specialized yet competitive. People live together in households that are locations 
for both consumer demand and labour supply, while firms similarly are locations both for consumer supply and labour demand. Hence, transactions in both the consumer and labour markets share a common need: connectivity between households and firms. Additionally, to reap the gains of scale from interdependence within networks, firms need good connectivity with each other and, because of sociability, so do households. Good connectivity is not exclusively about spatial connections: connectivity between firms needs the rule of law so that transactions can be enforced. Since the 1990s it has also become increasingly dependent upon good ICT. These three aspects of connectivity are best thought of as complements. Spatial connectivity creates the potential for transactions, but without the rule of law this potential will be frustrated. ICT has massively enhanced the scope for complexity. While this has raised the returns to scale, it has not made spatial connections redundant: even within ICT companies themselves, knowledge appears to be dependent upon spatial proximity.

Urbanization is the fundamental mechanism for good spatial connectivity. It generates connectivity in two different ways: it reduces the distance between households and firms, and it reduces the cost of transport per unit of distance between them. These two approaches require very different actions but they are complements rather than alternatives. Reducing the distance between households and firms involves increasing their density of occupation: firms and households would need to cluster more closely together. Reducing the cost of transport per unit of distance involves investment in transport infrastructure, such as roads and rail lines, and organizing the transport services that use it, such as bus companies and railway companies. Although these are distinct, over a wide range they are complements because of those same forces of scale and specialization which are the bedrock of productivity. As the density of occupation in any two locations increases, there is more scope for reaping scale economies in transport links between them and consequently more scope for specialization in tasks and the skills needed for them. These complementarities eventually reach their limit, depending upon the technologies used. For any given transport technology, at some point increases in density start to increase the unit cost of transport. This is due to congestion, the most evident example being a traffic jam. In summary, productivity depends upon connectivity, and the two inputs into connectivity are density and transport.

\section{Connectivity and the triple miracle of productivity}

To get more specific about how density and transport are best used in building an efficient city, we need to distinguish between three different types of household-firm connectivity. One is the connectivity that supports the labour market: how workers and firms are best connected.

The other two are differently-constrained types of connectivity between producers and consumers that support product markets. Depending on the characteristics of the product, it may be much easier to transport consumers to the product, or the product to consumers. The archetypal product in the former category is a cup of coffee, made in local cafes to which consumers walk. Thus, the connectivity required for this type of product is between the producer 
and the local market. The archetypal product in the latter category is one such as a specialized piece of equipment that is made in a single factory and then distributed to customers all around the world. Thus, the connectivity required for this type of product is between producer and the international market.

Hence, the labour market, the market for locally traded goods, and the market for internationally traded goods, each benefit massively from connectivity. In each, connectivity enacts a distinct miracle of enhanced productivity. But because the three forms of connectivity are distinct, each requires distinct contributions from density and transport. This is what we now explore.

\section{Connectivity and the miracle of productivity in the labour market}

Connectivity in the labour market enables the efficient matching of differentiated workers to differentiated jobs. In the labour market of a super-city such as London, the typical worker can access 2.5 million jobs within a 45 minute commute. Not only does this enable a high level of allocative efficiency - appropriate workers finding appropriate jobs - but more importantly, it enables dynamic efficiency. It provides an environment in which investment in highly specialized skills, and the creation of highly specialized jobs which need them, become financially viable. In London, almost any specialized skill will find a market, and almost any specialized task will find a qualified worker. Thus, connectivity is conducive to specialization, and specialization is critical for skill accumulation. An efficient city thereby promotes human capital accumulation. This may be the most important mechanism by which urbanization raises the productivity of ordinary people.

Connectivity in the labour market requires distinct forms of density and distinct forms of transport. Each of these has implications for how the city should be built. Because large numbers of people must travel to and from work at similar times, distances must be short and transport services must be able to cope with extreme peaks and long troughs. Mass transit systems, such as buses and trams, are therefore necessary and should have peak-period priority over individualised means of transport such as cars. One implication for density is that housing should be located as near as possible to places of work. For example, in retrospect, the post-1994 mass housing policy of South Africa was clearly mistaken in locating new housing far away from centres of employment. But because of the scale economies in transport services noted above, high density of occupation is also helpful so that many workers live close to the same bus or rail station. For example, the bus-rapid-transit system being installed in Dar es Salaam will struggle to be financially viable because the population is too dispersed for the planned bus stations to have a sufficiently large pool of commuters within easy reach. Hence, residential density and dedicated mass transit systems are the key investments which enable the miracle of productivity enacted in the labour market of an efficient city.

\section{Connectivity and the miracle of productivity in the market for locally traded goods}


Cups of coffee produced and sold in a cafe are at one extreme end of the spectrum of transportability, but many products and services are consumed predominantly within the city where they are produced. So defined, the category is an important component of both production and consumer expenditure.

Scale and specialization still matter...

Nevertheless, a cafe provides a useful concrete way of visualizing how scale and specialization apply to the production of locally traded goods, just as they do at to the production of internationally traded goods such as garments. The difference is the constraint on where the product can be sold: the cup of coffee must be within walking distance of potential customers, whereas the garment can be shipped anywhere in the world. To produce cups of coffee a cafe must have dedicated equipment. To produce a range of choice of coffees it will need a range of different equipment. The production of the more complicated cups of coffee involves several distinct tasks; in a high-productivity cafe these are each performed by different people, each of whom develops specific skills. Delivering choice and productivity thus requires that specialist equipment and specialist staff are kept fully occupied, and this requires a high level of demand. But people are not willing to travel long distances merely to buy a cup of coffee and so the extent of demand depends upon the density of consumers. If there is not enough demand within walking distance, the cafe cannot operate at an efficient scale: its workforce sits idle part of the day, and is less specialized; its equipment is less intensively used. But so far we have only considered the technical productivity of a single cafe; now introduce the scale economies reaped at the level of the market. For dynamic efficiency, if the local demand for coffee is large enough, then it will support several cafes which compete against each other and over time this will generate much larger gains in productivity.

The city grows until it reaches equilibrium...

If scale and specialization matter even for cafes, they most certainly matter for the general category of locally traded goods and services. Now consider a city which produces only such locally traded goods, and which is therefore self-sufficient, consuming only what it produces. Obviously, no actual city is entirely self-sufficient; it consumers some goods from abroad, and others that are produced in the rural economy. But it is still illuminating to think of the selfsufficient city because it is particularly simple. What determines how large such a city grows?

Growth generates a virtuous circle in which as the population grows, the scope for scale and specialization increase. The resulting increase in productivity increases incomes which attracts further people to the city. However, as the city grows, the costs of connectivity increase. To see this, imagine a representative locally traded productive activity, located at the centre of the city where it was easiest for the average worker to commute to it, and for the average consumer to travel to purchase the output. As the city grows, although production and consumption of the activity grow in tandem, the average distances that have to be travelled to work and to consume 
increase. Further, as more people travel to the city centre at some point it becomes congested: the efficiency of transport services declines. The increase in production reduces average costs due to additional scale economies, but the increase in distance and the onset of congestion increase the average cost of connectivity. Depending upon the characteristics of the activity, and the technologies used to achieve connectivity, at some point any further increase in size would raise the costs of connectivity by more than it lowered production costs. At this point the city has reached the size at which it maximizes the incomes of its inhabitants.

Whether the city grows beyond this size, or indeed stops growing before it is reached, depends upon what happens in the rural economy from which migrants are drawn. While ever average incomes net of the costs of connectivity are higher in the city that the surrounding rural economy there will be an incentive for further migration. Hence, the size of the city is determined not just by the economics of the city itself, but by the economics of rural production. As the surrounding population is drawn to the city, rural incomes rise since there is more land per person. If migrants to the city can earn the average urban income and face the average urban costs of connectivity, then equilibrium is reached once average urban income net of the average costs of connectivity is equated to rural income. While this is equitable, it need not be efficient. Quite possibly on the criterion of efficiency the city might have grown too large: for example, the additional migrants generate very high marginal costs of connectivity but themselves only face average costs: this is typical of congestion which is caused by marginal users of transport services but suffered equally by all users.

The extent of productivity growth generated by such urbanization depends upon the characteristics of the technologies used in production and connectivity. The available production technologies for different products are globally fairly standard, ranging from those for which the gains from scale and specialization are modest, to those where they are dramatic. How far along this range an African city goes will depend upon its choices of connectivity technologies. Even those African cities that have very large populations may have such low connectivity that only those activities which need modest market size are viable. In effect, such cities may be little more that accumulations of adjoining towns, each largely self-sufficient. Towns may cluster together in a quasi-mega-city rather than be spread more evenly across the country because inhabitants benefit from a few activities which despite poor connectivity serve a city-wide market. But the productivity gains would fall far short of those generated in a genuine mega-city such as London or Singapore, in which good connectivity across the city enables many goods and services to reap the productivity benefits of a mass market.

\section{Connectivity and Productivity in the Market for Internationally Traded Goods}

The same forces of scale and specialisation apply to the production of goods whether they can only be sold locally, or are sold on world markets. However, if a good is sold on world markets, scale and specialization are not offset by the spatial limitations on demand. In consequence, firms are much larger and more specialized. The most obvious class of goods that are globally 
tradable are manufactures, though scale and specialization can apply even more powerfully to some globally tradable services such as finance. As an example of scale and specialization in a manufactured product, take buttons. Buttons are a very simple product which consumers around the world all use. It might be expected that they would therefore be produced in many cities all around the world. In fact, two-thirds of the world's buttons are produced in a single city. The city has no natural advantages, nor is it the home of some globally dominant button producer: there is no dominant producer. Rather, it has developed an enormous cluster of specialist button firms. Why would a button producer choose to locate in such a cluster? While buttons themselves can be easily shipped around the world, some of the key inputs are highly local. For example, tacit knowledge, such as information about fashion trends being adopted by competitors, can be picked up over a drink in a local bar, but is not available to button firms in other locations. Over time, the city has developed a deep pool of skilled and specialist labour, so a firm is less vulnerable to the loss of a key worker. These and many other advantages pinion button producers to the cluster.

Clusters such as this one depend upon three distinct types of connectivity. Most obviously, they need to be able to ship produce to global markets. This implies being close to a well-functioning port or airport. Cities that are unable to provide such connectivity are unlikely to break into global manufacturing markets

\section{Technologies for Connectivity:}

In summary, to harness the huge productivity potential of scale and specialization, good connectivity is essential. This is the case for each of the three 'miracles of productivity' - the labour market, locally traded production, and internationally traded production - but each needs a distinctive form of connectivity. In consequence, this implies a different balance between the two means by which connectivity is achieved: density and transport.

Recall that the key difference between those goods and services which can be traded internationally and those which can only be traded locally, is their cost of transport to the consumer. Hence, in the trade-off between reaping economies of scale and proximity to the consumer, internationally traded goods will be located for scale, usually implying clustering near to other similar firms. In contrast, locally traded goods will be dispersed around the city, sacrificing some scale economies for greater proximity to consumers.

Even among locally traded goods there is a spectrum of transport costs. At one end of the spectrum, costs are so high relative to value that the product needs to be within walking distance of the consumer. In consequence, the greater is the spatial density of residence the larger will be the market for such goods. At the other end of the spectrum, such as specialist products and services which are only bought infrequently, even high residential density may be insufficient to support a market within walking distance that is sufficiently large to reap critical scale economies. The scale economies may be so important that the most spatially efficient pattern for 
such goods is for all suppliers to cluster at one location within the city. For example, all the jewellery shops in a city may locate on the same street because consumers place a high value on having a wide range of choice. In such cases good urban transport becomes important so that consumers can reach the cluster at reasonable cost.

The transport costs for most locally traded goods and services lie between these two extreme bounds. They would benefit from a city-wide market, but if transports services are poor and density is low, they operate for a much smaller market and consequently sacrifice significant scale economies. Within this range, the better is connectivity the more opportunities there are for locally traded goods to reap scale and specialization. An important example is the retail distribution of food. Where transport services are poor, consumers will need to be within walking distance of a food shop. This will constrain the size of shop, and also the number of shops that a consumer can reach. Where transport is good, a city may be served by a few hypermarkets around its edge, each able to reap large scale economies, but each competing with the others.

In an efficient city people producing both internationally traded and locally traded goods, people will travel to both types of workplace and also travel to shop. However, the transport requirements for these three activities will differ. For the production of internationally traded goods to reap scale and specialization, many workers must come together, implying that large numbers of commuters must travel to a central place such as an industrial zone daily and at the same time. For the production of locally traded goods people will also have to travel daily and at the same time, but the locations of employment will be more dispersed across the city. For shopping trips, journeys will not need to be synchronized and they will be less frequent.

Each of these types of journey benefits differentially from density and transport services. The production of internationally traded goods is highly dependent upon good transport services. In their absence firms may resort to dormitory-style worker accommodation which is both costly and drastically reduces the quality of life, requiring higher wages as an offset. Production of locally traded goods is highly dependent upon density, which by enlarging the market, generates scale economies and competition. Shopping benefits from both: high density but poor transport will generate productive-but-dispersed retailing; low density but good transport will generate productive shopping malls; high density and good transport will generate a productive central shopping district; low density and poor transport will generate low-productivity, dispersed retailing.

Hence, choices of appropriate technologies for connectivity will influence the structure of production, and the productivity of the workforce. We now consider these technologies in greater detail.

\section{Technologies for Connectivity: Building Density}


We now consider the deployment of technologies that create density. There are three different types of density: that appropriate for homes, that for production for the international market, and that for production for the local market.

\section{Residential density}

Residential density is simply the number of people who live per square kilometre. Directly, high residential density facilitates sociability: people can interact with each other more easily, which is likely to be life-enhancing. But high density contributes to productivity indirectly by making it possible to reduce distances between households (as consumers and as workers) and firms. Evidently, whether this potential is realized depends upon the location of firms. If, as in the Paris banlieu, the locations of high residential density are far from job opportunities, it remains unrealized. But if residential density is very low then no matter where firms locate they cannot be close to a large numbers of consumers and workers.

Residential density is thus conducive of productivity and there are two ways of increasing it: crowding and height. Crowding achieves increased density by reducing the average amount of floor space per person; height achieves it by adding storeys. Both of these options come at a cost, but the cost is likely to be somewhat different. Especially at the modest levels of income typical of Africa, a reduction in floor space almost inevitably reduces the quality of life. Height, in contrast maintains floor space and hence the quality of life, but is more expensive than single storey construction.

The trade-off between reduced floor space and extra height depends upon the provision of infrastructure, the quality of construction, and the extent to which the city is able to reap the three miracles of productivity. The initial installation of water, sewerage, and electricity beneath a building are fixed costs which are largely invariant to how many storeys are built on top of it. Similarly, if the home is to be built of substantial materials, it will need sound foundations which are also largely invariant to whether it is single-storey or multi-storey. Most crucially, if the city has succeeded in generating the three miracles of productivity, the land within the city will become valuable because it is the scarce resource that determines whether a household can participate in the benefits. Being scarce, it will be valuable, and so be a significant fixed cost invariant to the number of storeys that are built on it. If the investments in infrastructure, foundations and land purchase are significant components of the overall costs of the building, then adding storeys will, over a range, actually reduce the unit cost of floor space. Building a second and third storey is more expensive that building the first, but the fixed costs are spread over a more square metres. In contrast, if the single storey structure is built of flimsy materials, lacks infrastructure, and is in a city that has failed to release the potential of the three miracles of productivity, it can be built very cheaply, so that any greater height would continuously increase the unit cost of floor area. Hence, it is no surprise that African slums are overwhelmingly singlestorey. 
Once the number of storeys is increased beyond one, technological constraints tend to cluster structures into three types. For high-income households, in many parts of the world two-storey structures with some surrounding land have become an archetypal family home. While they are two storey structures they are often even lower density than slums, since high-income households choose to purchase more space: both floor area and plot size. Because of the low density, this is not a viable form of housing for the mass of the population in a large middleincome city since maintaining connectivity would impose too large a burden upon transport.

For ordinary households in a middle-income city, the technology that best reconciles floor space with density is likely to be an apartment in a block of four of five storeys. Above five storeys, the maintenance of decent quality of life requires an elevator and this involves a quantum increase in the cost of the structure. Hence, five storey structures spread the fixed costs of infrastructure and foundations over the maximum amount of floor space while avoiding this quantum increase in costs. In Africa such structures are rare, although the Government of Ethiopia is now building them in Addis Ababa at a unit cost of around \$10,000 net of the cost of land. This provides a lot of density without sacrificing floor space and hence preserves a decent quality of life.

Only if land becomes very valuable does it become economic to bear the quantum increase in cost involved in an elevator. Apartment blocks can then be high-rise, but the unit cost will be high because of the additional construction costs. The Government of Angola commissioned a Chinese construction company to build a high-rise dormitory town outside Luanda, but the unit costs of apartments are in excess of $\$ 100,000$ and so far beyond the means of ordinary households.

The technological menu for residential density can thus be approximated to four types of building: shacks, houses, apartments and high-rise. A city in which shacks predominate is indicative of a lack of investment in homes and hence is a symptom of low household incomes, low land values, and a lack of infrastructure. In sum, the city has failed to harness the potential for enhanced productivity. A city in which high-rise predominates, such as Singapore and New York, has evidently arrived at very high levels of productivity, while probably also being geographically constrained so that land is too valuable for houses to be economic. The technologies most appropriate for a middle-income city are likely to be a mixture of apartments and houses. The apartments will be near the city centre, and occupied by ordinary households, while the houses will be is the suburbs and occupied by skilled workers with higher incomes. No major African city currently has this mix of housing.

While high residential density enables the connectivity required for high productivity, whether it is realized depends upon the proximity to firms. The labour market matches workers to jobs, but many workers will get somewhere to live before they find of job, or will change job. In order for the matching process to be as efficient as possible, workers should not limit their search to those jobs which are close to their current homes. Hence, the simplest and cheapest way in which workers can live near to their jobs is if households are readily able to move home within the city. 
In practice, the only mechanism by which this can happen is through an active market, whether for rental or purchase.

\section{Density for the production of locally traded goods}

The production of some locally traded goods is much more efficient if it can serve a city-wide market and if firms can cluster together: for example, firms providing business services may benefit from being close to similar firms. For other locally traded goods the key requirement is a lot of demand within walking distance. These two different needs for connectivity consequently benefit from different strategies of location.

For those goods that need a city-wide market, and benefit from being near each other, the likely spatial solution is to cluster them together in the centre of the city. This is such a common feature of cities that there is a special term for it: the Central Business District, or CBD. The firms in the CBD serve a city-wide market of customers, both consumers and other firms in the city that need their services. A CBD can only exist if there is sufficient land in the centre of the city that is available for building the structures that such businesses need, notably shops serving consumers, and offices which will typically be occupied by services to local business such as accountants and lawyers. Since cities grow gradually, this is likely to require a change of use from whatever has been initially located near the city centre. So, there has to be some mechanism whether through a land market or through government intervention, by which facilitates this process.

For those goods that need to be within walking distance of where consumers live, a radically different spatial solution is needed. Businesses need to be dispersed throughout the city rather than clustered together. An ideal location might be on the ground floor of a five-storey apartment block: in effect, the business sits beneath a lot of consumer demand and so has as large a market as possible within walking distance. An implication of this is that policy should not try to zone some areas as being purely residential and others as commercial.

\section{Density for the production of internationally traded goods}

The spatial requirements for the production of internationally traded goods are radically different. The archetypical firm producing for the international market is in the manufacturing sector, the output of which is readily standardized and readily transported. Modern global manufacturing is input-intensive: many inputs are brought to the factory, a few processes are then undertaken, and the output is passed on, whether to other firms or to consumers. Hence, although such firms do not need to be near to local consumers, they need to have good access to transport arteries that link them to global markets, namely ports and airports. Further, to reap those scale economies of production that are generated at the level of a cluster rather than an individual firm, they need to be near each other. This suggests that their primary requirement is to be clustered together near an airport or port, or preferably both. Lagos is currently the only really large African city that has ready access to both types of international connectivity. 
As with the CBD, even if a city has a port or airport, a cluster of firms can only emerge around it if sufficient land is transferred from other uses, and if common infrastructure services such as electricity, water and sewerage are installed on the site. A common means of organizing this is to create an export zone.

While firms producing for the international market need good connectivity to that market, they also interact with the economy of the city. Primarily this is through the labour market, though over time links to firms providing business services may also develop. So, the export zone needs good connectivity to its labour force. In the early growth phase of Chinese manufacturing this was achieved by the grim means of housing workers in on-site dormitories, though this obviously sacrificed liveability for proximity and required compensatory increases in wages in order to attract workers. An approach more compatible with liveability is for high-density housing to be located near to the zone, and for there to be good transport links between the zone and the city.

\section{Technologies for Connectivity: Transport}

We now consider the other technological means of achieving connectivity, transport infrastructure and services. We focus in turn on each of the three key needs for connectivity, the labour market, firms producing for the local market, and firms producing for the global market.

\section{Transport for a workforce}

In an efficient city, many jobs will be spatially concentrated in the CBD and in an export zone. Other jobs will be dispersed throughout the city, in firms that are serving consumers in their neighbourhood. Work times tend to be coincident, which is a consequence of scale and specialization, and so the need for transport-to-work will be heavily peaked. Only a few transport technologies are able to move masses of people between their homes and concentrated destinations at common times of day. A few mega-cities have been able to afford underground systems, but for most middle-income cities this is prohibitively expensive. The alternatives all require investment in dense road networks. Much of the cost of a dense urban road network is that is takes up land: a good network can occupy 30 percent of the city. One consequence is that even a good road network may not be a substitute for residential density. A road network leaves other options open: in ascending order of investment cost, they are to restrict usage of much of the road network so that buses can be dominant; to build dedicated routes for Bus Rapid Transit (BRT); and to supplement roads with commuter rail systems. If none of these technologies are deployed, a large city will become gridlocked as private incentives lead to high levels of congestion. Gridlock destroys connectivity and hence productivity.

Which of these systems is economically appropriate will depend upon the density and per capita income of the city. With low density, neither the investment required for BRT, nor that for rail, is likely to be viable because stations will lack sufficient proximate populations to generate 
demand. Similarly, low income will limit demand. But per capita income reflects productivity, so that a failure to invest in connectivity can trap the city into low income.

The inter-dependence of density, transport and productivity implies that the technologies appropriate for density and transport are matched. A low-density city with transport reliant upon walking, which is what currently characterizes many African cities, condemns people to low productivity. But piecemeal provision of transport investment in a low-density city, and piecemeal provision of residential density in a city without transport investment, will both be wasteful. Investment in density and investment in transport are complements and need to increase together.

The exceptions to this are a few large high-income cities, such as Atlanta and Los Angeles. These have been able to achieve connectivity through a radically different strategy of very low densities of both homes and jobs. Such low densities would make mass transit systems prohibitively expensive. However, by combining these low densities with very high investment in road networks, reliance upon private cars for both work travel and consumption does not generate gridlock. The high connectivity enables productivity and hence incomes to be sufficiently high that households can afford the necessary investment in cars. However, there are two reasons to doubt that this model is viable for Africa. First, the long car journeys implied by high dispersion imply very high use of gasoline and this is only affordable in a cheap-gasoline economy such as the USA. Secondly, these cities only grew once ordinary Americans were already sufficiently rich to afford a car and for their cities to afford the large investments in road networks. In contrast, African cities are growing while ordinary people are poor and road networks are limited. As a result, gridlock is already common in Africa's large cities. Given African conditions, the model of high-density and mass transit is likely to be more feasible than that of low-density homes and jobs, highway networks, and private cars.

\section{Transport for firms producing locally traded goods}

Firms that serve only neighbourhood markets have little need for transport services: their clients are proximate. So the group of firms that need good transport are those clustered in the CBD. Some of these firms serve consumers, while others provide business services to other firms in the city. While distinct, these two types of demand for transport services are complementary and so make it easier to link the CBD to the rest of the city. While the key transport need of business services is that their workforce can easily reach them at the prescribed peak times, firms selling to consumers need transport services that work more evenly throughout the day. Hence, the offices and shops located in the CBD complement each other. Any of the mass transit systems needed for a workforce will involve high fixed costs of operation. The transport demand generated by shops complements this by being non-peak and so spreading the fixed costs over more usage. In those high-income cities that have not invested in mass transit, shops have usually relocated to malls located on the periphery of the city where they can be reached by private car without generating gridlock. This denudes the CBD of is consumer traffic and so 
concentrates transport demand only on the peak periods. In African cities ordinary households cannot afford a car, and so shops may be better located in the CBD along with business services.

Transport for firms producing internationally traded goods

Africa is an extremely fragmented continental market, being divided into 54 countries. As a result, the typical African national market is very small by global standards. Further, barriers to trade, both with neighbouring countries and with global markets, are high. This is partly due to poor transport infrastructure and partly due to bureaucratic impediments such as customs and police check points. Between them, small national markets and impediments to trade reduce the size of Africa's cities. This in turn implies that the typical firm in an African city has limited opportunities for scale and specialisation.

Africa's landlocked countries have limited access to global markets for urban-produced goods: connectivity is to a considerable extent out of their control. However, every African landlocked country has several neighbours. Many products are potentially tradable in regional markets, but not readily supplied from global markets. This may be because the cost of transporting the good or service from global suppliers is too high, or because regional tastes are sufficiently different from the products that are globally produced to give local suppliers a large knowledge-based advantage. Improving the connectivity for this group of regionally tradable products offers considerable scope for enhancing productivity. Most African cities would grow significantly larger and firms within them would become more productive, if trade with neighbours became easier. Rather than most activity shifting to a single hub city in the region, cities would become more specialized. As a result they would reap gains in productivity and nearly all cities would grow.

The transport infrastructure needed by regionally tradable products is partly that which supports connectivity to consumers in neighbouring countries, and partly that which supports clustering of such firms within a city. In Uganda, the new Kampala Ring Road potentially supports both objectives. By relocating to the ring road, firms can avoid the congestion of central Kampala and so shorter the time to reach consumers in neighbouring countries. Further, by opening up land on the periphery of the city, the ring road makes it easier for firms to cluster together. These two benefits of the ring road can both be considerably enhanced by complementary regulatory policies. Connectivity to neighbouring countries depends more on border crossing times than on congestion in Kampala, and so it makes sense to improve the efficiency of border posts. Similarly, clustering depends upon access to land. While the ring road improves physical access to land at the periphery of the city, this can be complemented by improving the ability to acquire legal title to land.

\section{Investing in the city}

Cities are defined by the structures that are built within them. The process of investing in urban structures is central not just for the cities themselves but for the entire economy: in a developed 
economy they typically constitute over half of the entire national capital stock. Were this investment process to be impeded, the national economy could not develop. There are three types of urban structures, defined by differences in their functions and their ownership. The needs of household residence are met by investment in housing, which is typically owned by households themselves. The needs of production are met by investment in commercial property, which is owned by firms. The needs of connectivity are met through infrastructure, which is owned by government. Investments in structures face distinctive challenges: they are far more interdependent than other types of investment and so need far more coordination; individual investments in structures are 'lumpy' and so require lumpy finance. We discuss these in turn.

\section{Coordinating investments in structures: common knowledge}

Investments in structures are unlike those in equipment in three important respects. They depreciate far more slowly, both through physical wear and tear and through technological obsolescence. For example, in Oxford many academics still work in buildings that are hundreds of years old, but none of the equipment they use will be much older than a decade. Once built, structures are immobile, so that even those that are marketable are only locally tradable. Finally, much of their value is determined by complementarities with other structures in the vicinity. In combination, these features imply a high degree of path dependence. The first structures to be built in a city determine the opportunities for investments in other structures in their vicinity. In turn, path dependence implies that investors need to anticipate what other structures will be built in the locality. This is far more acute in respect of structures than equipment, the other major form of investment: the future extends much further, complementarities with other localized investments are far greater, and the pertinent investors form three distinct communities between which information may not flow well. This creates a major problem of coordination: investors need to know what other investors are going to do.

The process of building a city involves thousands of distinct investment decisions by each type of investor, spread over many years. Evidently, this vast need for coordination both between actors and over time has the potential for indeterminacy and mistakes. Indeterminacy can arise because expectations are self-fulfilling: for example, if potential investors expect others to invest, they would be astute to do so, whereas if they expect others not to invest they would be foolish to do so. Mistakes can arise because some potential investors may base their decisions on expectations that turn out to be wrong.

Social psychologists have discovered that the key to solving coordination problems is to generate common knowledge (Thomas et al., 2014). Common knowledge is distinct, and more demanding, than shared knowledge which means simply that everyone knowing the same things. Shared knowledge only becomes common knowledge if everyone knows that everyone knows the same things. This implies that ideally, investment intentions need to be made sufficiently publicly observable that each investor is confident that other investors are observing the same 
information. There are two complementary means of generating common knowledge about investment in structures: anchor structures and land prices.

Anchor structures are those that have particularly large complementarities with other structures that might subsequently be built in the vicinity. Once the anchor structure is built, since it cannot be reversed or moved, it becomes rational for other investors to build neighbouring structures. For example, if a large factory is built in the middle of nowhere, it radically enhances the economics of investing in houses, commercial property and infrastructure in the neighbourhood. But usually a firm would be quixotic to build a factory in such a location. A more common form of anchor investment is infrastructure. This is because, dollar-for-dollar, investment in infrastructure is likely to have larger complementarities than investments in other structures. Infrastructure is an investment in connectivity so that its very purpose is to complement other investments. Investments in other structures are only inadvertently complements. Investments in infrastructure not only substantially enhance the returns on investment in neighbouring structures, they are readily observable. Hence, they generate new economic facts which are common knowledge. Early public investment in infrastructure can therefore ignite a benign pathdependent process by which the city gets built.

Markets are the major economic coordination mechanisms. As long as prices are readily observable, the market for urban land will generate common knowledge about the perceived value of land at different locations. In an efficient land market this value will reflect a rational expectation of potential, although this will still be subject to the indeterminacy noted above. Anchor infrastructure and an active market in urban land thus complement each other. Common knowledge about the infrastructure anchors expectations, land markets then generate appropriate valuations of the benefits of the infrastructure to potential neighbouring structures, and these values in turn become common knowledge by being revealed as prices.

Even with common knowledge, the efficient usage of urban land will evolve. As the city grows, it will be efficient to pull down old structures and replacing them with others. Residential structures will change from houses to multi-storey apartment blocks; where clusters of economic activity form, homes will be replaced by factories, offices and shops; as density increases, a higher proportion of the land area will need to be devoted to transport routes so that homes and commercial buildings will sometimes have to be sacrificed to make way for roads. These changes can only happen if urban land ownership is comprehensively registered, and if there is an active land market so that valuations are straightforward. Since new transport routes can be subject to hold-up by landowners along the route, there will also be a need for a legal process of compulsory purchase, something which has been internationally standard since the advent of railways.

\section{Financing structures:}


Structures are more demanding to finance than the other forms of investment: inventories and equipment. Inventories turn over rapidly and so can be financed by short duration instruments such as bills of exchange. The stock of equipment will typically be composed of many different items each of which is rapidly depreciating, so that it can be financed as a flow of small expenditures. In contrast, the financing of structures is lumpy: a block of apartments cannot be inhabited, nor a factory produce goods, until it is completed; a half-constructed road is useless for connectivity.

The financial requirements of investment in urban structures are enormous. Thinking ahead, as is necessary for African urbanization, the region will need to build many cities of around 5 million inhabitants. To live decently at the standard appropriate for middle-income countries, their average per capita income will need to be at least $\$ 5,000$, so the income of such a city would be around $\$ 25 \mathrm{bn}$. For a ballpark estimate of the infrastructure costs, a typical ratio of aggregate capital to aggregate output in middle-income countries is around 4.0, so the capital stock of teh city would be around $\$ 100 \mathrm{bn}$. Assuming around half of this capital is in the form of structures, the city would need around $\$ 50 \mathrm{bn}$ of financing for its structures. To put this in context, the typical African country currently has a sovereign bond market worth around \$2bn, and annual aid inflows are around $\$ 1 \mathrm{bn}$. No African government, and no individual company, could afford to finance the cost of building an entire city. The future financing of Africa's urban structures will rely primarily upon tapping into financial markets, domestic and international, and tapping into them on such a scale is not a trivial matter.

Each type of structure requires distinctive financing. Housing is best financed by a long-term mortgage. Commercial buildings are typically not owned by the firms which use them, but are leased by them from investment funds which buy them from a developer. The developer who initiates the building will finance the costs of land purchase and construction from a combination of high-risk equity capital and bank loans. The infrastructure of connectivity, such as a road network, is typically financed by the governing authority of the city or the country. To cover this expenditure the authority will need to issue debt, and for this debt to be serviceable, the infrastructure will need, directly or indirectly, to generate a substantial revenue stream.

Finance for housing.....

Currently, only 3 percent of African households have mortgages. In the absence of mortgage finance urban housing will predominantly be single-storey because few households will have sufficient savings to afford the lumpy investment required by greater height.

A basic requirement for private finance of housing is that it should function as collateral. This in turn requires several characteristics. One is that underlying ownership of the house should be legally secure. Since the ownership of the house cannot be more secure than the ownership of the land on which it is built, this implies that title to land should be unique and verifiable by a 
reliable legal process such as a court. The decision of the court should be reliably enforceable by a police authority.

A second characteristic is that the housing unit should be readily amenable to valuation since the collateral value of the property cannot exceed the lower bound of the range of estimates of realisable value. This implies that it should be built to a standard design rather than being idiosyncratic, and that the market in this standard unit should be sufficiently active for transactions to have revealed the valuation range. Once built, parts of the housing unit, such as the foundations, will be unobservable. Since these affect the value of the house, the lender must be able to ascertain that appropriate building standards were enforced during construction.

A third characteristic is that the lender must be able to verify the ability of the borrower to service the mortgage. Conventionally, this is done by direct evidence of income as provided by an employer, or if the borrower is self-employed, by the audited accounts of his enterprise. In urban Africa only a small minority of households have members in formal sector wage employment, or own formal enterprises subject to audit processes. Hence, they are unable to verify their income by these conventional means. A potential alternative is for income to be inferred from the history of verified expenditures, as provided by records of e-payments.

A fourth characteristic is that the collateral provided to the lender should be legally enforceable by the lender in the event of a specified lapse in repayments, such that the lender can evict the resident of the housing unit.

A fifth characteristic is that the annual debt service should be a small fraction of the mortgage, so that decent housing is affordable at modest levels of income. In turn, this depends upon the duration of the loan, and the nominal and real interest rates charged. In the OECD, typical mortgage structures are for loan durations of at least 20 years, and nominal interest rates under 7 percent. This enables people to borrow around four or five times their annual income. Typically in Africa, mortgage lenders charge nominal interest rates around 20 percent. With such high rates, regardless of the duration of the mortgage, most of it will be repaid in real terms in only a few years and so the feasible multiple of annual income is much lower. In macroeconomic environments where inflation will periodically rise to double digits, it may be appropriate to index the loan so that the annual debt service is calculated using the real interest rate, which will be correspondingly lower, an approach already adopted by many lenders in Ghana.

Finally, appropriate financial institutions must exist in sufficient numbers to provide a competitive market for mortgages. In the OECD, specialist institutions such as building societies/ savings-and-loan societies have been the main providers of mortgages because their cost base can be kept lower than that of banks: for example, they need less skilled staff.

Finance for commercial structures 
As noted above, in a typical OECD economy the financing of commercial buildings is complex. Finance for construction will be provided partly by equity capital of a developer, geared up by a bank loan. At this stage, the valuation of the completed property is subject to a wide range of uncertainty, so that the loan will be for considerably less than the cost. Since the loan is the senior claim on the company, the function of the equity component is to bear the risk. Because it is bearing risk, equity capital is expensive. To keep financing as cheap as possible, the loan will cover only the initial period of construction and leasing, at which point the developer will sell the occupied structure to an investment fund, repaying the bank loan from the proceeds and the equity, being released from bearing this risk, can be assigned to some new project. Because once it is built and occupied the valuation of the commercial structure is much clearer, the investment fund which buys it will not require such a high rate of return.

For this sequence of transactions to function, many preconditions need to be in place. As with housing finance, title needs to be clear, unique and reliably enforceable, implying that the courts function in a satisfactory manner free of influence from the corrupt and the politically powerful. Markets must be sufficiently deep for valuations to be clear. Over-and-above such considerations, to be able to access international finance there must be explicit freedom to remit profits abroad, and the currency needs to be convertible and reasonably stable.

\section{Finance for infrastructure}

A well connected city needs a huge investment in infrastructure and this can appear daunting to public authorities. However, the key insight into the finance of urban infrastructure is that with appropriate taxation it is entirely self-funding. This is because the entire rationale for efficient investment in infrastructure is that the productivity gains that it generates exceed its own cost. Most likely, the gains very considerably exceed that cost. Further, since the gains in productivity are localized in the city, they can only be accessed by firms and workers by producing and living on the land within the city. This makes the land within the city far more valuable per hectare than rural land. Indeed, the appreciation in the value of urban land comes close to fully reflecting the total gain in productivity. But if land ownership is publicly registered, it then becomes a straightforward administrative matter to tax this appreciation in land values. Not only is such a tax practical, it is also ethical and non-distorting. It is ethical because those who own the land contribute very little to its appreciation, which is the result of the combined neighbouring investments and many different people. It is non-distorting because the appreciation in land values is merely an economic rent for a scarce resource, rather than a return on the economic activity of the owner, so unlike in production, there is no behaviour by the owner to be distorted. Taxing the appreciation in land values can be done in a variety of ways, but the most straightforward is an annual tax based on the market value of land in the vicinity.

\section{Path Dependence and Low Productivity Traps}


Cities with good connectivity do not happen overnight. They get built gradually as a result of a sequence of millions of individual decisions of households, firms and governments. Different sequences lead to different outcomes: the process of city growth is highly path-dependent. Some sequences lead to good connectivity; others lead to cities that, even though they grow large, have levels of connectivity that condemn their inhabitants to low productivity and hence to poverty. Such sequences are traps of under-development: here we discuss some of them. Several of them can coincide, and this has indeed characterized much of African urbanization to date. They are the paths that future African urbanization needs to avoid.

\section{The trap of overcrowding and congestion}

African urbanization is happening at income levels that are much lower than the equivalent degree of urbanization in other regions. This is probably because African peasant agriculture has long been unproductive, with rapid population growth and the consequent reduction in land per person offsetting the modest pace of productivity enhancement from investment and innovation. In consequence, poor people have moved to cities even though they have not offered much prospect of a productive job.

Such households do not have the accumulated savings to make significant investments in housing, and so their default option is to build shacks. Because shacks are insubstantial, they are inevitably single-storey. To date, in many African cities this has been the dominant mode of settlement in the city. In consequence, as cities have grown, they have spread outwards rather than increasing in height.

Sprawling cities with low density of residence can only achieve good connectivity if there is massive public and private investment in transport: public authorities must invest in vast and dense networks of roads, and households must invest in cars. Atlanta and Los Angeles in the USA are examples of such cities. But for Africa this has not been a viable option. Ordinary households have been too poor to invest in cars; the public authorities have been too poor to keep abreast of the vast expansion in the road network that would have been needed given the rate at which their cities have spread. Instead of cities like Atlanta, urban sprawl has generated cities like Dar es Salaam, where the limited road network has been overwhelmed by the rise in population. As such cities spread outwards, two forces start to reduce connectivity.

As the edge of the city gets further from the centre, connectivity progressively deteriorates for new arrivals who settle at the edge of the city. As a result, the incomes of new arrivals living at the edge of the city progressively decline. As incomes at the edge decline, people become willing to accept higher density living in order to live near the centre. But because this increase in inner-

city density is not achieved by greater height it is at the expense of floor-space and so involves a sacrifice of wellbeing due to overcrowding.

Further, as more people attempt to use the limited road network, the core of the city becomes congested: transport routes are pushed into the usage range in which they are subject to 
diseconomies of scale. The virtuous circle of urban productivity growth goes into reverse: instead of additional households raising productivity for existing households, they lower productivity.

But while ever the productivity gains generated by even modest levels of connectivity enable ordinary workers to have higher living standards than remaining as farmers, migration will continue. Hence, overcrowding and congestion worsen until the combination of deteriorating living conditions and falling productivity fully dissipate the initial gains in living standards. Unless rural living standards have risen as a result of out-migration, the society is back where it started. Some economic rents generated by urbanization remain because they are captured by landlords, but even these are modest because the city has not raised productivity by much even for central locations.

\section{The trap of weak land rights}

The key function of clear rights to urban land is that it is a pre-condition for the emergence of a formal land market. Informal, non-legal markets can function in almost any conditions, but informality in land markets is distinctively limiting because, unlike the business of most informal markets, land is an asset. Asset transactions are only viable if the purchaser can rely upon some enduring extra-legal means by which the new ownership is recognized, such as sanction by the local community or the support of a gangland protection racket. In contrast, a formal market not only provides purchasers with the protection of the state, because transactions are readily observable and recorded it generates the public good of accurate valuation.

Weaknesses in the formal land market impede changes of land use. Firms cannot buy up land from low-density residential use to convert it into higher-density apartments or to create new clusters of commercial structures. They also impede the collateral value of buildings constructed

on the land, constraining investment in residential height. Even for middle-income migrants, if an investment in housing must be entirely self-financed, any structure beyond the minimalism of a shack is daunting, but undermining the collateral value of structures is even more important in the context of low-income migration.

As with the first trap, weak land rights thereby inhibit density, both for residence and for commercial clusters, and so frustrate the miracle of rising productivity.

\section{The trap of settlement prior to infrastructure}

Recall that one reason for the early installation of infrastructure is that it is a coordinating device: an irreversible, and therefore credible, commitment which is highly visible and so generates common knowledge. A further reason for early infrastructure is that if it is postponed until after settlement has taken place it is more costly and fraught to install. It is more costly because all the services that need to be located underground are easier to install at scale on clear sites rather than retrofitted piecemeal beneath existing structures. It is more fraught because the inevitable 
disruption to private homes generates indignant political protests. For example, Freetown grew rapidly during the civil war, at a time when the government was in no position to provide new infrastructure, and now that people have settled all available urban spaces, local opposition to road construction has perpetuated the severe lack of roads.

Settlement prior to infrastructure thus has similar consequences to the other two traps: poor connectivity frustrates the productivity potential of urbanization.

\section{The trap of informality}

If, due to one of the above traps, connectivity is poor, it inhibits the emergence of modern business organizations. In well-connected cities, the markets for locally traded goods are sufficiently large to enable firms to reap scale economies, and productivity is high enough to enable entry to global markets. In order to reap scale economies, firms have to become large. As the organization grows, it has little option but to formalize. Managing a large organization informally would usually be infeasible, grossly inefficient, or prohibitively costly. Formality brings with it transactions that are legally enforceable, bookkeeping that keeps track of finances, and access to formal credit markets. It also brings the firm onto the government's radar screen for taxation. If, however, connectivity is too poor to permit scale economies, firms remain small. For small firms, formalization may bring net disadvantages such as exposure to taxation, so they remain informal.

But by eschewing formality, business owners deny themselves the learning-by-doing through which they might gradually acquire the methods of modern business. Exposure to such methods might be a productivity escalator: for example, owners might learn how to formulate a business plan and present it to a bank. Hence, poor connectivity traps the urban economy into a small scale of enterprise. At small scale, informality outperforms formality on the criterion of private, static efficiency. But informality in turn traps the economy into stagnant productivity.

\section{The trap of high costs of production for internationally traded goods}

Even a city with very poor connectivity will be able to produce locally traded goods because firms do not face competition from producers located in cities with better connectivity. But internationally traded goods can only be produced in a city if its overall costs of production do not exceed that of global competitors. If the initial impetus for the growth of the city is to produce internationally traded goods then, because it starts competitive, it is likely to remain so as cluster scale economies drive costs down. An early example is the Sheffield cutlery industry. Firms initially located there because of abundant water-power, but even when this ceased to be relevant the city continued to dominate the global industry because of its cluster scale economies. However, if the initial impetus for the growth of the city is to produce locally traded goods, as is the case in Africa, as the city grows costs of production for all goods may rise due to congestion, making production of internationally traded goods unviable. 


\section{African sequences of urbanization contrasted with the Chinese sequence}

To date, African urbanization has typically been characterized by all of the above traps. Very poor people have flooded into cities pushed by population growth in the context of rural stagnation rather than by the dynamism of urban economies. Lacking savings, migrants have built shacks that caused cities to sprawl. Settling informally on land that lacked clear ownership rights, this migration froze land use and inhibited investment in structures. In turn, this inhibited the provision of infrastructure. Poor connectivity has locked business organizations into informality. Deepening the trap, the resulting low-productivity city did not generate sufficient income to provide a strong tax base to finance infrastructure.

The contrast with salient features of Chinese urbanization is striking. First, the rural situation was markedly different: coming out of a disastrous period of collectivization, it was relatively easy for agricultural reforms to generate rising rural productivity. This was reinforced by the onechild policy, and legal impediments to migration to cities. Hence, migration was more a response to urban growth than to rural desperation. Second, the extraordinarily high savings and investment rates that Chinese households adopted, aided by rising per capita incomes, provided the finance for investment in residential height. Both the reduced pressure of migration and rising density due to height reduced the pace of sprawl and so moderated the need to build new transport infrastructure. Investment in transport infrastructure could keep abreast of this moderated need for it because, as Chinese cities generated rising productivity, the resulting appreciation in land values was captured by city governments. As a result, China has managed to build cities with good connectivity, whereas to date Africa, with its very different sequence of urbanization, has not done so. Good connectivity has enabled Chinese firms to formalize and to learn the modern business methods that enable entry to global markets.

\section{Policies for Connectivity and Liveability}

Urbanization requires effective government. It depends upon massive private and public investment in structures that are long-lasting and interdependent. It depends upon the migration decisions of millions of households. The coordination of these myriad decisions requires both markets and public planning, and markets themselves require considerable public action.

Good connectivity is essential for productivity but it cannot happen without the active support of government authorities. Further, productivity is not enough: the English miracle cities of the $19^{\text {th }}$ Century inadvertently generated the tragedy of squalor. An active public social policy is necessary to prevent rising private incomes being offset by declining quality of life.

Connectivity and liveability do not happen without active government. Five types of government action are required: land registration; provision of public infrastructure and services for transport; provision of public social goods and services for decent quality of life; enforcement of those private behaviours which are socially beneficial but not individually advantageous; coordination 
of those private decisions which are interdependent; and revenue generation through taxation and debt to finance these activities.

Most African urbanization lies in the future, and could be shaped by the adoption of these policies. However, since the policies are not yet in place, past urbanization has been dysfunctional. In consequence, alongside the need to shape future urbanization, it is necessary to reshape past urbanization. Rectifying dysfunctional urbanization is both technically and politically harder than getting future urbanization right. Technically, because the costs of retrofitting the structures needed for connectivity and liveability is considerably higher than if they had been planned, the optimal retrofitted city will be different from the optimal planned city. It will require a series of compromises between the ex ante ideal and the ex post feasible. Politically, retrofitting may be even more difficult, because vested interests will either have to be accommodated or faced down.

\section{Land registration}

As the city grows, the parcels of land near its centre become suitable for more productive uses which make them increasingly valuable. The issue of who has the authority to decide on the evolving use of each individual parcel is logically entirely distinct from that of to whom the appreciation should accrue.

An efficient process of urban growth requires that the myriad decisions on changing usage should be decentralized to individual firms and households: there are far too many decisions to be managed through central planning. In consequence, an active land market in which the private usage rights of individual parcels can be bought by the firm or household to whom they are most valuable is fundamental to building an efficient city. This in turn requires clarity of the title to use each parcel. Usage rights might be conferred by outright ownership, or by leases of sufficient duration to warrant investment in the construction of long-lasting structures. Since land is not produced, the valid title to a parcel is entirely a social construct determined by recognized authority. In the absence of a unique public register of titles maintained by the pertinent public

authority, a land market cannot function properly.

While public action to confer clear private titles is essential, there is a strong case for capturing much of the appreciation in value for the public authority. The same process by which usage claims are registered can form the basis for taxation. We expand on this below in our discussion of public revenues.

To date in Africa the titling of urban land has usually not kept pace with settlement. In consequence, individual rights are confused and contested. This has had two unfortunate consequences: the process of investing in structures has been inhibited, and a potentially major source of finance for public authorities has been missed.

\section{The provision of public transport infrastructure and services}


Connectivity by means of transport services requires two distinct activities: the provision of the network of roads and rail lines, and the provision of the services that run on them.

No city has ever had its road or rail network generated by a market process. With negligible exceptions, usage of urban roads is invariably free, and so in the absence of government intervention there is little private incentive to provide them. Further, urban roads and rail systems are networks, so that the benefits of each individual road or rail line include its contribution to the whole. In consequence, these networks have to be planned by government. In rapidly growing cities this is a major task requiring a specialist team which is sufficiently resourced to gather data on the evolution of usage across the city and to make informed projections. As noted above, road planning and construction needs to keep ahead of settlement. Once people have settled on land they cannot reasonably be removed without compensation. Hence, the city authorities need to pre-empt private occupation of the public spaces that they anticipate will be needed as the city grows. A well-connected large city needs around $30 \%$ of its land devoted to roads; yet in large African cities less than $10 \%$ of the land area is currently so used.

Financing road construction can, to an extent, be done indirectly, by requiring developers who buy land from the public authority to build roads in accordance with the plan. When, more usually, the public authority directly finances the construction of roads, it does not itself need to be the constructor. This may be best done through open tendering.

In contrast to the infrastructure, the provision of bus services can be done through a decentralized process of a competitive market. Because bus services have some network features there may be a tendency towards monopoly. If this appears to be happening, there will be a need for regulation, but whether regulation is needed depends upon local circumstances. Urban rail services have more powerful network features than buses, and so have stronger tendencies towards monopoly. Urban rail services therefore need either to be privately run but subject to effective regulation, or to be directly owned by a public authority.

Because road usage is free, and each user inflicts congestion costs on other users without taking them into account, as the city grows, private usage will become excessive. In the absence of countervailing policies, this will impair bus transport and hence connectivity. Bus Rapid Transit (BRT) addresses this by providing dedicated roads for services; a less costly approach is to provide dedicated bus lanes.

\section{The provision of public goods and services for quality of life}

The devastating health hazards which hit the $19^{\text {th }}$ Century industrial cities demonstrate the distinctive urban need for some public services. However, cities generate not only more acute needs for some public services, but distinctive opportunities. I discuss these in turn.

Countering the adverse effects of overcrowding 
The key problems generated by overcrowding in slum conditions are disease and crime. The key counter to disease is clean water. Waste must be safely removed through a sewerage system, and clean water piped to homes. Installing conventional sewerage systems is costly, but in some large African cities even if they were installed there would not be enough rainfall to operate them.

New technologies enable sewerage systems to operate with more limited water supplies, but need to be planned in advance. Both piped water and sewerage are far cheaper to install in advance of settlement.

Slums are prone to street gangs which can reduce the quality of life for residents and increase the costs of business for firms. They can be countered through street lighting and policing. Once established, gangs are difficult to eradicate because they are able to reap the scale economies of organized violence. Hence, it is likely to be cheaper to pre-empt their emergence by providing lighting and policing at an early stage in settlement.

Harnessing the opportunities of residential density

Those public services which are provided for free, such as schooling, are subject to the same scope for economies of scale and specialisation as those services which are locally traded. Hence, it may be less costly to provide a given level of per capita service for a dense urban population than for a dispersed rural population. Being less costly to provide, the optimal level of provision is therefore likely to be higher. Cities can therefore offer better education, health, and specialist services than those feasible in rural areas. Since the gains from enhanced provision accrue to urban households, this provides a private incentive for migration over-and-above the gain in income. Since migration will continue until rural and urban living standards are equated, the gain in wellbeing from enhanced urban public services moderates urban wages. While urban workers face some costs that are higher than for rural workers, such as housing and commuting, and so need higher wages to compensate for them, good public services counter these effects. By organizing this enhanced service provision, and thus moderating the wages that firms need to pay to recruit workers, public authorities make it easier for their city to break into the market for internationally traded goods. As discussed above, crossing this threshold ignites an explosive growth process.

Evidently, to be able to seize the opportunities for high productivity in public services created by residential density, public authorities need to build revenue systems which finance provision. Effective public policy generates enhanced non-income wellbeing in cities, whereas without active public policy non-income wellbeing will be lower than in rural areas because of overcrowding.

\section{Enforcement}

An effective public authority has a monopoly on the use of coercive force. This gives it a unique power of enforcement which is valuable in many aspects of urbanization. 
At a basic level, public authorities are essential to enforce private property rights. Because building the city depends upon private rights over land and structures, this is fundamental to successful urbanization. For land registers and mortgage collateral to perform their core functions of supporting a market in parcels of land, and providing finance for investment in structures, they need well-functioning on-the-ground enforcement.

Beyond enforcement of property rights, public authorities are important for enforcing building regulations. Such enforcement has two distinct functions: coordination and information. Costs are often lower if design is standardized rather than leaving all aspects of design to be idiosyncratic: firms can coordinate on a common publicly-set standard. Further, some features of a structure, such as its foundations, can only be observed during construction. It is therefore useful for standards concerning foundations to be publicly enforced so that subsequent purchasers can know what they are buying. Standardization and information make valuation easier and this in turn enhances the collateral value of structures.

As the city grows, an increasing proportion of its inner area will be needed for roads. Since the authorities cannot accurately anticipate how much it will grow, even if retrospective conversion of land use to roads is costly, it will at times be necessary. Ever since the introduction of railways in the 1840s, governments have recognized that in order to acquire the land needed for transport routes it is necessary to have the power of compulsory purchase at fair value.

There may also be a role for public authorities to enforce greater residential density than would be produced by the market. As land values rise in and near the core of the city, this provides a market-based private incentive for greater residential density. However, residential density is a public good as well as a private one. It reduces the need for transport, which by easing congestion benefits everyone, and by concentrating consumer demand it supports a larger, more competitive market, benefiting everyone. Especially in societies with very high levels of inequality, such as Kenya, the high density occupation that ordinary households need may otherwise be crowded out by the ability of high-income groups to buy large plots near the core of the city for single household occupation.

\section{Coordination}

Private investments in structures face a coordination problem: investors need to know what other investors are likely to do. Achieving coordination requires common knowledge: information that investors know is shared by other investors. The early provision of public infrastructure generates common knowledge. Because such investments are irreversible, they are more credible than plans. Because their physical presence makes them readily observable, they generate common knowledge whereas plans, being less observable, would at best generate only shared knowledge: many investors might see the plans, but would not know whether other investors had seen them. The coordination benefits of early public infrastructure are additional to the direct benefits of the services provided by it. 


\section{Revenue}

Public authorities need to make two distinct types of expenditure: the capital costs of public infrastructure and the running costs of those public services where costs cannot be fully recovered from charges. Since the capital costs of public infrastructure must be incurred somewhat in advance of the productivity and liveability benefits they generate, there is a need for financing. As more generally with infrastructure, the most likely means by which urban infrastructure can be financed is for the public authority to issue bonds. However, while this enables the infrastructure to be built, the bonds will only be bought if there is a credible prospect of a revenue stream from local taxation that is sufficient to service them.

Because cities with good connectivity generate large gains in productivity for their inhabitants, there are many potential tax points. Transactions within the city could be subject to a sales tax, resident households made subject to a local income tax, and firms made subject to a local business tax. But the least distorting form of taxation may be the appreciation in urban land values. As the city becomes more productive, in order to benefit from the enhanced productivity that it enables, firms and households must locate within it. As this happens, the value of land parcels appreciate according to the connectivity that each provides. This appreciation capitalizes the additional productivity provided by locating on the parcel. Hence, if the infrastructure is worth providing, the appreciation in land values that it generates must exceed the cost of providing it, most likely by a wide margin. Further, the appreciation in land values is an economic rent rather than a payment to a factor of production: that is, it does not depend upon the effort of the land or its owner. In consequence, taxing the rent does not change productive behaviour: that is, it is not distorting. The appreciation of land values does not require the tax point to be a land transaction: there is considerable scope for falsifying the transaction in order to evade such taxes. An alternative is an annual tax based upon a market-based estimate of the average value of land in the locality.

\section{Rectifying Dysfunctional Urbanization}

The typical African city does not provide good connectivity. Informal settlement covers much of the area of the city with single-storey shacks; businesses have not been able to cluster together because the land market is not sufficiently liquid; insufficient roads have been built; and insufficient infrastructure for public services such as sewerage, water and electricity. Rectifying this legacy is important, but difficult. It involves a series of trade-offs.

Much of the land currently occupied by shanty settlements will need to be put to better use: some of it for transport infrastructure, some for clusters of businesses, and some for multi-storey dwellings. The changes of use to business clusters and multi-storey dwellings depends upon the legal infrastructure for a land market; but the private investment decisions underlying these changes of use face the standard problem of coordination. Until the land occupied by the shanty settlements has the transport infrastructure appropriate for private investment in structures, 
change will be slow and such private investment in upgrading dwellings as occurs may only be appropriate because incentives are so heavily distorted. Hence, retrofitting transport routes through the shanty settlements may be the first, necessary policy intervention. Following this, giving residents of shanty settlements clear, registered, marketable rights to the land which they occupy will gradually enable efficient changes of use. Some Indian cities have pioneered coordinated, but voluntary changes of use, as shanty residents have agreed collectively to exchange their current holdings for smaller plots in new areas with upgraded infrastructure. In OECD societies, city authorities have also resorted to compulsory clearing of shanty settlements, with the provision of appropriate alternative accommodation. Such coordinated clearance lowers the cost of reconstruction compared to piecemeal change, and avoids the holdup problem frequently faced by commercial developers who assemble economically large parcels of land by a gradual and secretive process of purchasing adjoining holdings.

While retrofitting of sewerage systems may be an urgent priority for public health, it is clearly better to coordinate such retrofitting of social infrastructure with the plans for reshaping the shanty areas for greater connectivity. For example, an inner-city shanty settlement may rapidly switch to commercial use once transport routes and land rights are introduced, so that a sewerage system might become redundant.

\section{The balance between rectifying past deficiencies and shaping future urbanization}

In addition to be more costly than green field urban development, retrofitting is far more demanding of public officials. Decisions are technically and politically more complex. Technically, retrofitting is an intricate and information-intensive process. Politically, the loss of existing usage rights to land is likely to be resisted, and during reconstruction people's lives are disrupted. Both the financial costs and the burden on public officials are important because the current state of Africa's cities suggests that to date, urban authorities have not even been able to keep abreast of population growth. Yet what is ideally needed is not only to keep ahead of future population growth, but to address the accumulated backlog. Doing these together would require a quantum leap in the financial and organizational capacity of public authorities. In some situations quantum change may be feasible: for example, the Government of Uganda has recently transformed the public management of Kampala, shifting political authority from a locally elected city council to the equivalent of a national ministry staffed by technocrats. But in the absence of such a quantum increase in capacity, public authorities face a painful trade-off. The more effort is devoted to rectifying past deficiencies in existing settlements, the further will new provision fall behind population growth. Because of the cost differential, each existing resident benefiting from retrofitting will be at the expense of more than one new resident who settles informally and may worsen congestion for all, instead of occupying a well-connected dwelling and thereby enhancing productivity for others.

\section{The Political Economy of Good Policies}


Around the world, many cities provide productive and liveable conditions for their inhabitants. Most African cities have yet to do so. Ultimately, this reflects a lack of effective governance of the urbanization process. The building blocks of effective governance can usefully be grouped under four headings: authority, rules, institutions and a critical mass of political support for good policies.

\section{Authority}

The public policies needed for the creation of a city that is productive and liveable evidently require an entity with the authority to design them and implement them. The process will be impeded both if there is a lack of authority, and if authority is divided across too many distinct entities. Many African cities suffer from both of these problems.

On a fundamental aspect of urbanization, the ownership of urban land, there is a lack of authority. While in principle national legislatures have the authority to determine ownership, or to create public entities which can do so, in practice in most cities ownership of much of the land remains confused: no public entity is recognized as having the practical authority to evict people who occupy a parcel of land. Until such practical authority is created, no urbanization process can be successful.

Authority is also often divided between many distinct entities. Typically, several government ministries will each have some responsibilities for urban policies, and the land occupied by a city which has grown rapidly may span the responsibilities of several different local government entities. Even where responsibilities are clearly delineated, this poses three layers of coordination: between different government ministries, between different local government entities, and between national and local government. Often, the mechanisms that might make coordination work are lacking. Yet more seriously, responsibilities are often not clearly delineated, resulting in disputes about turf.

\section{Rules}

Urbanization involves many decisions that need to be taken again and again. The cost of taking such repeat decisions can be greatly reduced by rules. Rules guide decision-takers and also flag up instances in which there are good reasons to breach them: because a rule is being breached, the decision will be subject to scrutiny. Rules can usefully cover many aspects of urbanization such as procedures for public procurement of private land; provision of road space; provision of social infrastructure; and building standards. Rules are the easiest part of governance, and African cities are probably not lacking in them. But some of these rules are colonial inheritances that are not appropriate for modern African conditions. For example, across Anglophone Africa urban authorities were expected to conform to the 1947 Town and Country Planning Act, adopted by the British Government for planning in British cities. Building standards and minimum sizes of plots were set at such lavish levels that even by the 1980s in Britain they were being diluted. They were radically inappropriate for urbanization in low-income economies. 
Colonial policies were not always copies of British policies but could still become highly dysfunctional. In respect of land rights, whereas in Britain land titles had been clear for centuries, in Africa the colonial authorities resisted the emergence of marketable rural land rights. As a result, as African cities grew far beyond their tiny colonial cores, the land newly settled lacked marketable titles.

\section{Institutions}

Institutions are not merely rules on paper; they are living organizations consisting of people working in teams. They need a mandate, capacity and motivation.

The mandates of urban authorities inherited upon Independence were manifestly inappropriate. Africa inherited urban authorities that were suitable only for small, colonial administrative centres. They were not equipped to provide for the sort of cities that Africa would need. Once Independent, African governments established both ministries of economic planning, and ministries of urban planning. However, the two were divorced from each other, and both rapidly became divorced from budgetary realities. Ministries of finance came to be the critical entity for economic policy decisions, but their focus was on annual macroeconomic management. As five year plans fell out of fashion, planning ministries lost influence. The responsibility for urban policies was often never clearly delineated between national, regional and city authorities. Within national government, urbanization policies were assigned to ministries of urban affairs, and ministries of housing. In consequence, the critical role of urbanization in long term national economic development fell between the institutional cracks.

Lacking revenues, urban authorities have not invested in the capacities needed either for urban planning or for practical implementation on the ground. Nor are capacities merely about numbers of staff and their individual qualifications. As with firms, knowledge is quantized not primarily in individuals but in teams of specialized people who are motivated to further the objectives of the organization. Building such teams is a difficult task of senior management. An appropriate balance of specialists needs to be recruited and trained; while motivation depends upon a careful blend of incentives linked to monitored performance, and persuasion aimed at internalizing organizational objectives.

\section{Support}

Authority, rules and institutions can all be frustrated if those individual interests in conflict with the common good are too powerful. In Africa rapid informal urbanization has created three such interests.

First, many poor rural households see their interest best served by migrating to cities. But they do not take into account the increased congestion that their move to cities inflicts on existing urban dwellers. Rising congestion happens because urban authorities lack the practical mechanisms either to restrict migration (as Chinese urban authorities were able to do), or to offset it by 
substantial and continuous improvements in transport infrastructure. Since congestion reduces connectivity, at the margin African rural-to-urban migration thus tends to reduce productivity.

Secondly, poor urban households living precariously as squatters in shanty towns, see their interest as being to defend their occupancy of land. Their rights of occupancy are insufficiently strong to be able to sell the right to ownership, but strong enough to prevent any other potential user from evicting them. Again, this arises because urban authorities lack the practical power either to confer full marketable land rights on squatter occupancy, or to evict squatters from the land they occupy. Often squatters are settled in single-storey shacks in inner-city slums. This is a very inefficient use of such land: more valuable uses would be commercial and multi-storey residential. A new estimate of the cost of land misallocation in the Kibera slum of Nairobi, puts it at well over $\$ 1 \mathrm{bn}$.

Thirdly, politically well-connected individuals and companies take advantage of the confused state of rights to urban land to acquire quasi-legal claims on parcels in the sprawling city. For example, the ownership of large parts of Kampala is claimed by a mere six individuals. Similarly, a small number of politicians and senior civil servants claim ownership of much of Kibera. Since cities are enlarging, this is not a one-off opportunity, but a continuous process whereby new sites become valuable, and sites in the core city are becoming increasingly valuable. Again, the problem is that these claims are neither sufficiently strong for the claimants to sell the land to more productive users, nor sufficiently weak that their claims can be declared invalid. Even an indication that a parcel of unused land might be wanted for a valuable use is often sufficient to attract the de facto claim achieved by squatting and the quasi-legal claim achieved by a courtroom challenge. The title to land can be no more secure than the practical legal process of courts which determines whether a claim is valid, and the practical policing process which enforces eviction.

In dealing with these private interests there are two options: facing them down or buying them off. Facing them down requires that the authorities directly responsible for urban policies have sufficient political support to overcome these opposing private interests. Typically, the public authorities directly responsible for urbanization are relatively lowly in the political hierarchy. The constituency for good urban policies therefore needs to be strengthened by building alliances.

One key alliance is with more powerful parts of government. Creating powerful and unified urban authorities, clarifying the roles of different entities that must work together, and creating coordinating mechanisms by which this happens, are key tasks of national leadership. As explained in previous sections, successful urbanization generates large increases in productivity, but effective authority is necessary to unleash this process. In consequence, these enormous economic gains can be thought of as the rents to good authority. During the decade 2004-14 the performance of African economies, and much of the attention of Ministries of Finance, was dominated by the rents on natural resources. With the decline in commodity prices these rents 
have collapsed. The potential rents on successful urbanization are both far larger and far more sustainable that these resource rents but as yet they are insufficiently recognized by Ministries of Finance. Rapid urbanization will be the major structural change of the coming decade and constitutes a massive one-off opportunity. It would be timely for Ministries of Finance to give it appropriate attention.

The other key alliance is with citizens. By definition, most people lose if vested interests frustrate successful urbanization. Hence, in a democracy it is in principle possible to build a majority against them. For example, the handful of people who have quasi-legal claims to the land beneath Kampala and Kibera could be overwhelmingly outvoted by those who would gain from reassignment of these claims. But ordinary citizens do not automatically recognize their best interest: the economics of urbanization has to be communicated to people in ways that they can grasp. Such communication is the core skill of good political leaders.

Sometimes, however, no feasible political alliance will be able to face down private interests. For example, if the people living in shanty towns perceive their claims to occupancy to be threatened they will riot. This need not imply that urban authorities are condemned to the status quo. Given the huge potential gains from successful urbanization, if vested interests cannot be faced down, they can be bought off. Recall that land misallocation in Kibera is wasting over $\$ 1 \mathrm{bn}$ of potential value. Squatters in Kibera, and the politicians and officials who claim ownership, could be awarded shares in full marketable legal title, with a further share awarded to the public authorities. This would enable the land to be bought by developers who could then put it to much more valuable uses. All three entities could be substantially better off than the frustrating waste implied by the status quo.

\section{References}

Hidalgo, C. 2015, Why Information Grows: the Evolution of Order from Atoms to Economies, Allen Lane.

Thomas, K., O.S. Haque, S. Pinker and P. DeScioli, 2014, The Psychology of Coordination and Common Knowledge, Journal of Personality and Social Psychology, 107, 657-676. 